\title{
PENERAPAN METODE PEMBELAJARAN KUIS BINGO DALAM MENINGKATKAN HASIL BELAJAR MAHASISWA PADA MATAKULIAH RUANG VEKTOR
}

\section{THE APPLICATION OF BINGO QUIZ LEARNING METHOD IN IMPROVING STUDENTS' LEARNING OUTCOMES IN VECTOR SPACE COURSE}

\author{
Deby Erdriani*, Dewi Devita \\ Universitas Putra Indonesia "YPTK" Padang \\ Jalan Raya Lubuk Begalung,Kota Padang, Sumatera Barat 25145 \\ "de2bye@upiyptk.ac.id
}

\begin{abstract}
This study aims to obtain better student learning outcomes and comprehension of the theories provided. In this study, the experimental method carried out was in the form of bingo games to review the lessons at the previous meeting, where in the previous meeting the theory was given by lecture method. By using the bingo game method, students were expected to become more active in class. Data between the experimental and control classes both pretest and posttest were tested using the Kolmogorov-Smirnov test. The result of the test found that not all data were normally distributed. After that, comparing the posttest data between the experimental and control classes with the Mann Whitney test showed that the value of Significance or Asymp. Sig. (2 -tailed) is smaller than the 0.05 probability which get the hypothesis of accept Ha. Based on the "test statistics" output in the Mann Whitney test, it is known that the Asymp. value Sig. (2 -tailed) of 0.434 is less than probability <0.05. Therefore, as the basis for the decision making of the mann whitney test above, it can be concluded that it accepts Ha. Thus, there are differences found in learning outcomes between the experimental and control classes. Because of the significant differences, the formulation of the research problem has been answered that there is an influence of the use of learning methods with bingo games on student learning outcomes. After that, comparing the learning outcomes in the experimental class between pretest and posttest obtained a hypothesis test of learning outcomes between pretest and posttest by using the Wilcoxon test between pretest and posttest in the experimental class then obtained a positive rank between the learning outcomes for the pretest and posttest. There are 26 positive data $(N)$ which means the 26 students have increased their learning outcomes from pre-test scores to post-test scores, the mean rank or average increase is 18.83, while the positive rank or sum of the ranks is 489, 50.
\end{abstract}

Keywords: Bingo game, learning evaluation, vector space.

\begin{abstract}
ABSTRAK
Penelitian ini bertujuan untuk memperoleh hasil belajar mahasiswa lebih bagus dan pemahaman akan teori yang diberikan lebih mudah. Pada penelitian kali ini metode Eksperimen yang akan dilakukan berupa permainan bingo untuk mereview pelajaran pada pertemuan sebelumnya, dimana pada pertemuan sebelumnya sudah diberikan teori dengan metode ceramah. Dengan metode permainan bingo dapat membuat mahasiswa lebih aktif dalam kelas. Data antara kelas eksperimen dan control baik itu pretest maupun posttest diuji dengan menggunakan uji Kolmogorov-Smirnov didapatkan bahwa tidak semua data berdistribusi normal. Setelah itu membandingkan data posttest antara kelas eksperimen
\end{abstract}


dan control dengan uji mann whitney, menunjukkan nilai Signifikansi atau Asymp. Sig. (2 -tailed) lebih kecil dari probabilitas 0,05 maka didaptakan hipotesis terima Ha, berdasarkan output "test statistics" dalam uji mann whitney diketahui bahwa nilai Asymp. Sig. (2 -tailed) sebesar 0,434 lebih kecil dari probabilitas < 0,05. Oleh karena itu sebagaimana dasar pengambil keputusan uji mann whitney diatas maka dapat disimpulka bahwa terima Ha. Dengan demikian dapat dikatakan bahwa ada perbedaan hasil belajar antara kelas eksperimen dan control, karena ada perbedaan yang signifikan maka rumusan masalah penelitian terjawab yakni ada pengaruh penggunaan metode pembelajaran dengan permainan bingo terhadap hasil belajar pada mahasiswa. Setelah itu membandingkan hasil belajar dikelas Eksperimen antara pretest dan postest maka didapatkan uji hipotesis hasil belajar antara pretest dan posttest dengan menggunakan uji Wilcoxon antara pretest dan posttest dikelas ekperimen maka diperoleh . Positif rank antara hasil belajar untuk pres test dan post test, disini terdapat 26 data positif $(\mathrm{N})$ yang artinya ke 26 mahasiswa tersebut mengalami peningkatan hasil belajar dari nilai pre test ke nilai post test, mean rank atau rata-rata peningkatan adalah sebesar 18,83, sedangkan rangking positif atau sum of ranks adalah 489,50 .

\section{Kata kunci: Permainan Bingo, evaluasi pembelajaran, ruang vektor}

\section{PENDAHULUAN}

Pelajaran yang berhubungan dengan matematika sudah dipelajari dari mulai sekolah dasar sampai perguruan tinggi. Metode yang digunakan juga cendrung sama yaitu menyampaikan teori dengan metode ceramah kemudian diberi soal-soal latihan yang dikerjakan dikuliah dan diakhir pertemuan diberi tugas-tugas berupa beberapa soal untuk dikerjakan dirumah dan dikumpulkan pada pertemuan berikutnya. Kemudian sebelum ujian biasa diberikan quis untuk mereview pelajaran yang akan diuji pada ujian semester baik itu Ujian Tengah Semester (UTS) atau Ujian Akhir Semester (UAS). Metode yang diberikan seperti ini tidak membuat mahasiswa efektif dalam belajar, cendrung mereka menjadi bosan sehingga kadang-kadang tugas dan latihan yang diberikan tidak maksimal pengerjaannya. Sehingga mengakibatkan nilai akhirnya menjadi kurang memuaskan.

Banyak metode yang bisa dilakukan pada proses pembelajaran, menurut Sobri Sutikno (2009: 88) menyatakan, "Metode pembelajaran adalah cara-cara menyajikan materi pelajaran yang dilakukan oleh pendidik agar terjadi proses pembelajaran pada diri peserta didik dalam upaya untuk mencapai tujuan". Metode pembelajaran ada macammacam yaitu 1) metode ceramah, pada umumnya digunakan dalam pembelajaran, 2) Metode tanya jawab, 3) Metode pemberian tugas, 4) Metode demostrasi dan 4) Metode eksperimen.

Dari macam-macam metode diatas tujuannya sama memberikan pembelajaran yang baik kepada peserta didik supaya pelajaran yang diberikan mudah dipahami dan diserap 
dengan baik oleh peserta didik. Dengan metode yang ada, pendidik khususnya dosen disini dituntut bagaimana menciptakan suasana belajar dikelas lebih aktif dan kreatif dengan memakai metode pembelajaran. Tujuan akhirnya untuk memperoleh hasil belajar mahasiswa lebih bagus dan pemahaman akan teori yang diberikan lebih mudah.

Pada penelitian kali ini metode Eksperimen yang akan dilakukan berupa permainan bingo untuk mereview pelajaran pada pertemuan sebelumnya, dimana pada pertemuan sebelumnya sudah diberikan teori dengan metode ceramah. Dengan metode permainan bingo dapat membuat mahasiswa lebih aktif dalam kelas, sesuai dengan penelitian yang telah dilakukan sebelumnya oleh Tian Oktaviani, Endah Rita Sulistya Dewi dan Kiswoyo (2019) yang berjudul "Penerapan Pembelajaran Aktif Dengan Metode Permainan Bingo Untuk Meningkatkan Hasil Belajar Matematika”. Dalam penelitian disimpulkan bahwa pembelajaran aktif dengan metode permainan bingo dapat menciptakan lingkungan belajar yang menyenangkan, di mana siswa akan menjadi aktif dalam proses pembelajaran, lebih mampu bekerja dengan teman-teman lain, suasana kelas lebih hidup dan mampu mencapai tujuan pembelajaran yang diinginkan. Sehingga siswa akan termotivasi untuk bersaing sehat dan siswa tidak merasa bosan selama proses pembelajaran. Kesimpulan dari penelitian ini adalah penerapan pembelajaran aktif dengan metode permainan bingo dapat meningkatkan hasil belajar matematika.

Menurut Muhammad Mushfi, pembelajaran Matematika selama ini masih banyak melakukan hal-hal yang monoton seperti mencatat sebanyak-banyaknya soal dari papan tulis di buku mereka. Pembelajaran seperti itu membuat peserta didik bosan dan kurang tertantang. Peneliti bereksperimen untuk mengimplementasikan metode permainan BINGO. Penelitian ini bertujuan untuk mendeskripsikan implementasi pembelajaran dengan menggunakan permainan BINGO untuk meningkatkan kemampuan siswa dalam memecahkan masalah belajar dan meningkatkan hasil belajar Matematika. Kemampuan peserta disdik dalam memecahkan masalah belajar Matematika melalui permainan BINGO dapat diterapkan pada siswa yang memiliki kemampuan akademik yang heterogen. Implementasi pembelajaran tersebut mampu meningkatkan hasil belajar peserta didik dengan maksimal. Selain itu, permainan BINGO juga mampu meningkatkan antusiasme dan keaktifan siswa sehingga siswa termotivasi dan senang dalam mempelajari muatan pelajaran Matematika. 
Metode permainan bingo ini dilakukan pertemuan terakhir sebelum UAS, dimana ini merupakan pengganti kuis yang biasanya dilakukan dengan ujian tertulis, tapi pada permainan bingo kuisnya dilakukan secara lisan. Judul penelitian yang adalah

\section{PENERAPAN METODE PEMBELAJARAN KUIS BINGO DALAM MENINGKATKAN HASIL BELAJAR MAHASISWA PADA MATAKULIAH RUANG VEKTOR.}

\section{METODOLOGI}

Metode dalam penelitian ini adalah eksperimen dengan desain kuasi ekperimen. Pemilihan sampel pada kuasi eksperimen dilakukan dengan teknik non random sampling yaitu purposive sampling. Bentuk design kuasi eksperimen yang digunakan adalah Nonequivalent control group design. Populasi dalam penelitian ini adalah mahasiswa teknik informatika (IF), sedangkan untuk sampelnya adalah 2 kelas. Pada awal penelitian dilakukan prestest untuk melihat kemampuan masing-masing kelas, setelah itu diakhir pertemuan dilakukakn posttest masing-masing kelas.

Disini dosen mengkombinasikan metode drill dengan permainan bingo. Menurut Nur Baiti Nasution (2017. p 33-40), metode dril adalah metode yang menekankan pada latihan intensif dan berulang-ulang dengan tujuan agar siswa dapat menguasai keterampilan yang bersifat spesifik. dapat meliputi jenis dan desain penelitian, populasi dan sampel penelitian, metode validitas dan reliabilitas instrument penelitian, serta teknik analisis data yang digunakan. Data yang diambil pada metode ini ada 2 kali pengambilan data pertama data sebelum metode ini dilakukan, data kedua setelah metode ini dilakukan. Disini ada perbandingan antara kelas control dengan kelas eksperimen.

\section{PEMBAHASAN}

Menurut Sugiyono metode penelitian eksperimen adalah metode penelitian yang digunakan untuk mencari pengaruh treatment tertentu (perlakuan) dalam kondisi yang terkontrol. Uji hipotesis yang digunakan bertujuan untuk mencari pengaruh metode pembelajaran (x) dengan menggunakan permainan bingo terhadap hasil belajar (y). Variabel y merupakan hasil belajar berasal dari hasil pengukuran, sedangkan variable $\mathrm{x}$ merupakan hasil pengamatan. 
Hanya variable dependen yang dilakukan uji normalitas dan homogenitas. Dalam hal ini variable hasil belajar (y) perlu diuji normalitas dan homogenitas. Berikut table uji normalitas masing-masing nilai di kelas eksperimen dan kelas kontrol. Hipotesis yang diajukan dalam penelitian atau hipotesis awal adalah perbedaan hasil belajar antara menggunakan metode permainan dengan metode biasa. Uji normalitas masing-masing nilai di kelas eksperimen dan kelas kontrol

\section{Tabel 1. Tests of Normality}

\begin{tabular}{lrrrrrrr}
\hline & \multicolumn{3}{c}{ Kolmogorov-Smirnov $^{\mathrm{a}}$} & \multicolumn{3}{c}{ Shapiro-Wilk } \\
& Statistic & df & \multicolumn{1}{c}{ Sig. } & Statistic & df & \multicolumn{1}{c}{ Sig. } \\
\hline Nilai_1_Kelas_Eksperimen & .156 & 38 & .020 & .929 & 38 & .019 \\
Nilai_2_Kelas_Eksperimen & .072 & 38 & $.200^{*}$ & .975 & 38 & .527 \\
Nilai_1_Kelas_Kontrol & .172 & 38 & .006 & .903 & 38 & .003 \\
Nilai_2_Kelas_Kontrol & .145 & 38 & .043 & .932 & 38 & .024 \\
\hline
\end{tabular}

\section{a. Lilliefors Significance Correction}

*. This is a lower bound of the true significance.

Dengan melihat uji Kolmogorov-Smirnov,maka :

Nilai 1 kelas eksperimen, memiliki nilai sig. 0,020 ini lebih kecil dari $\alpha=0,05$ maka dapat diartikan data tidak berdistribusi normal

Nilai 2 kelas eksperimen, memiliki nilai sig. 0,200 ini lebih besar dari $\alpha=0,05$ maka dapat diartikan data berdistribusi normal

Nilai 1 kelas kontrol, memiliki nilai sig. 0,006 ini lebih kecil dari $\alpha=0,05$ maka dapat diartikan data tidak berdistribusi normal

Nilai 2 kelas kontrol, memiliki nilai sig. 0,043 ini lebih kecil dari $\alpha=0,05$ maka dapat diartikan data tidak berdistribusi normal

Tabel 2. Kesimpulan Uji Normalitas

\begin{tabular}{lll}
\hline Nilai / Kelas & Eksperimen & Kontrol \\
\hline Nilai 1 & Tidak Normal & Tidak Normal \\
Nilai 2 & Normal & Tidak Normal \\
\hline
\end{tabular}


Selain itu normal atau tidaknya sebuah data dapat kita lihat dalam tampilan Histogram 1 dan Histogram 2 berikut:

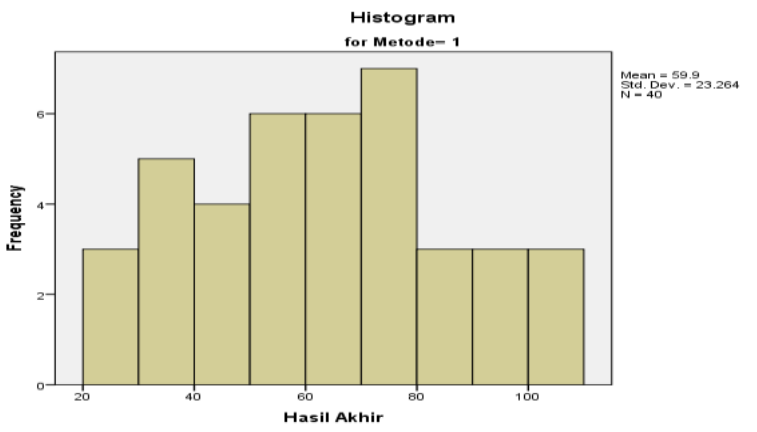

Histogram 1. Metode 1 Kelas Eksperimen

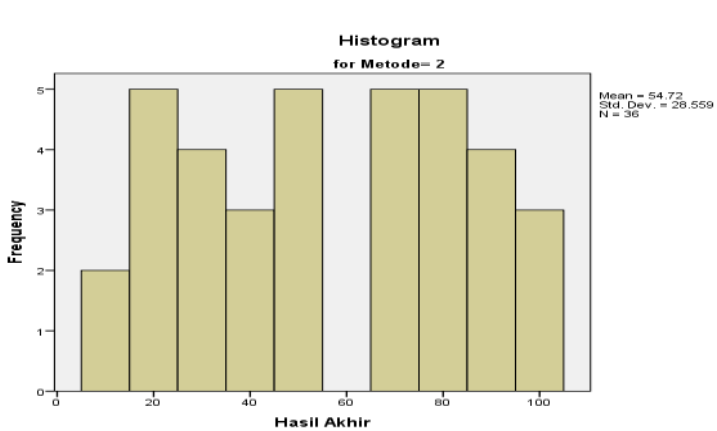

Histogram 2. Metode 2 Kelas Kontrol

Dari gambar diatas dapat dilihat penyebaran nilai dari masing-masing mahasiswa baik kelas eksperimen mau kelas control. Dapat dilihat bentuk kemiringan dan lebarnya sama. Hal ini menunjukkan bahwa penyebarannya dan bentuknya sama. Kemudian lihat puncak tertinggi kedua histogram ternyata tidak sama antara keduanya yang berarti terdapat perbedaan median. Maka uji mann whitney u test telah terpenuhi yaitu terdapat kesamaan bentuk dan penyebaran data.

Berdasarkan Rumusan Hipotesis penelitian komperatif pada artikel Sahid Rahajo . Untuk mengetahui apakah ada perbedaan rata-rata hasil belajar siswa antara kelas eksperimen dan control, maka perlu membuat sebuah rumusan hipotesis (dugaan) penelitian sebagai berikut :

$\mathrm{H}_{0}$ : Tidak ada perbedaan rata-rata hasil belajar mahasiswa antara kelas eksperimen dengan kelas control

$\mathrm{H}_{\mathrm{A}}$ : Ada perbedaan rata-rata hasil belajar mahasiswa antara kelas eksperimen dengan kelas control

Maka tidak perlu dilakukan uji homogenitas, langsung ke uji hipotesis menggunakan uji Mann-Whitney U, terlebih dahulu dicari apakah terdapat perbedaan hasil belajar antara kelas eksperimen dengan kelas control dengan mengunakan uji Mann-Whitney. Dengan Hipotesis alternative adalah ada perbedaan antara hasil belajar kelas eksperimen dan kelas control maka diperoleh hasilnya. 
Tabel 3. Ranks- Mann- Whitney Test

\begin{tabular}{llccc}
\hline & Kela & & Mean & Sum of \\
& S & N & Rank & Ranks \\
\hline Hasil & 1 & 40 & 40.38 & 1615.00 \\
Akhir & 2 & 36 & 36.42 & 1311.00 \\
& Tota & 76 & & \\
& 1 & & & \\
\hline
\end{tabular}

Tabel diatas menunjukkan mean rank atau rata-rata peringkat tiap kelompok. yaitu pada kelompok kesatu rerata peringkatnya 40,43 lebih tinggi dari rerata peringkat kedua yaitu 30,60. Melihat perbedaan rerata peringkat kedua kelompok tersebut dapat ditampilkan secara statistic seperti table dibawah ini:

Tabel 4. Test Statistics ${ }^{\mathrm{a}}$

\begin{tabular}{lr}
\hline & Hasil Akhir \\
\hline Mann-Whitney U & 645.000 \\
Wilcoxon W & 1311.000 \\
Z & -.782 \\
Asymp. Sig. (2-tailed) & .434 \\
\hline
\end{tabular}

Tabel diatas menunjukkan nilai Signifikansi atau Asymp. Sig. (2 -tailed) lebih kecil dari probabilitas 0,05 maka hipotesis atau terima Ha, berdasarkan output "test statistics" dalam uji mann whitney diatas diketahui bahwa nilai Asymp. Sig. (2 -tailed) sebesar 0,434 lebih kecil dari probabilitas $<0,05$. Oleh karena itu sebagaimana dasar pengambil keputusan uji mann whitney diatas maka dapat disimpulka bahwa terima Ha. Dengan demikian dapat dikatakan bahwa ada perbedaan hasil belajar antara kelas eksperimen dan control, karena ada perbedaan yang signifikan maka rumusan masalah penelitian terjawab yakni ada pengaruh penggunaan metode pembelajaran dengan permainan bingo terhadap hasil belajar pada mahasiswa.

Uji Wilcoxon sering kali digunakan sebagai alternative dari uji paired sample $t$ test. hal ini tidak salah sebab jika data penelitian anda tidak berdistribusi normal (uji normalitas) maka data tersebut dianggap tidak memenuhi syarat dalam pengujian statistika Parametik khususnya uji paired sample t test. Oleh karena itu, perlu adanya tindakan yang harus dilakukan peneliti agar data penelitian yang dikumpulkan masih tetap dapat diuji atau dianalisis yakni dengan cara melakukan metode statistic non parametric.

Sementera itu, sebagaimana uji paired sample t test, disini uji Wilcoxon juga digunakan untuk mengetahui ada tidaknya perbedaan rata-rata dua sampel yang saling berpasangan. Data penelitian yang digunakan dalam uji ini idealnya adalah data yang 
berskala ordinal atau interval. Uji Wilcoxon tidak diperlukan data penelitian yang berdistribusi normal. untuk kebutuhan data Penelitian melalukan penilaian atas hasil belajar siswa sebelum (pre test) dan sesudah (post test). Metode pembelajaran diterapkan dikelas tersebut maka diperoleh data dari hasil belajar yang dilihat dari nilai akhir, yang ingin diteliti. Hipotesis alternatif adalah " ada perbedaan hasil belajar pre test dan post test, yang artinya ada pengaruh pengunaan metode pembelajaran permainan bingo terhadap hasil belajar.

Tabel 5. Tabel post tes - pre test (Ranks)

\begin{tabular}{llrcc}
\hline & $\mathrm{N}$ & $\begin{array}{c}\text { Mean } \\
\text { Rank }\end{array}$ & $\begin{array}{c}\text { Sum of } \\
\text { Ranks }\end{array}$ \\
\hline $\begin{array}{l}\text { post test - pre } \\
\text { test }\end{array}$ & $\begin{array}{l}\text { Negative } \\
\text { Ranks } \\
\text { Positive }\end{array}$ & $9^{\mathrm{a}}$ & 15.61 & 140.50 \\
& $26^{\mathrm{b}}$ & 18.83 & 489.50 \\
& $\begin{array}{l}\text { Ranks } \\
\text { Ties }\end{array}$ & $5^{\mathrm{c}}$ & & \\
& Total & 40 & & \\
\hline
\end{tabular}
a. post test $<$ pre test
b. post test $>$ pre test
c. post test $=$ pre test

Awalnya peneliti ingin menggunakan analisis statistika parametric dengan uji paired sampel $\mathrm{t}$ test untuk uji hipotesis diatas, namun karena penelitian tersebut tidak distribusi normal maka peneliti menggunakan alternative uji Wilcoxon.

1. Negative ranks adalah Ada penurunan pengurangan dari nilai pre test ke nilai post test

2. Positif rank antara hasil belajar untuk pres test dan post test, disini terdapat 26 data positif (N) yang artinya ke 26 mahasiswa tersebut mengalami peningkatan hasil belajar dari nilai pre test ke nilai post test, mean rank atau rata-rata peningkatan adalah sebesar 18,83, sedangkan rangking positif atau sum of ranks adalah 489,50

1. Negative ranks adalah Ada penurunan pengurangan dari nilai pre test ke nilai post test

2. Positif rank anatara hasil matematika untuk pres test dan post test, disini terdapat 26 data positi $(\mathrm{N})$ yang artinya ke 26 mahasiswa tersebut mengalami peningkatan hasil belajar dari nilai pre test ke nilai post test, mean rank atau rata-rata peningkatan adalah sebesar 18,83, sedangkan rangking positif atau sum of ranks adalah 489,503. Ties kesamaan nilai pre test dan posttest disini adalah 5, sehingga dapat dikatakan ada 5 nilai yang sama antara pre test dan post test 
3. Ties kesamaan nilai pre test dan posttest disini adalah 5, sehingga dapat dikatakan ada 5 nilai yang sama antara pre test dan post test.

Tabel. 6 Test Statistics ${ }^{a}$

\begin{tabular}{lr}
\hline \multicolumn{2}{c}{ post test - pre test } \\
\hline Z & $-2.861^{\mathrm{b}}$ \\
Asymp. Sig. (2-tailed) & .004 \\
\hline
\end{tabular}

a. Wilcoxon Signed Ranks Test

b. Based on negative ranks.

Berdasarkan output diatas "test Staistics" diatas diketahui symp. Sig (2-tailed) bernilai 0,004, karena nilai 0,004 lebih kecil dari < 0,005 maka dapat disimpulkan bahwa Hipotesis alternatif diterima artinya ada perbedaan antara hasil belajar untuk Pre Test dan Posttest sehingga dapat dapat disimpulkan bahwa : ada pengaruh penggunaan metode pembelajaran permainan bingo terhadap hasil belajar pada mahasiswa.

\section{SIMPULAN}

Metode permainan bingo yang dilakukan sebagai pengganti kuis diakhir pertemuan dapat merubah hasil belajar yang diperoleh oleh mahasiswa. Uji pada kelas eksperimen apakah ada perubahaan hasil belajar dengan menggunakan metode permainan bingo, maka diuji lagi dengan uji Wilcoxon antara pretest dan posttest dikelas ekperimen maka diperoleh . Positif rank antara hasil belajar untuk pres test dan post test, disini terdapat 26 data positif $(\mathrm{N})$ yang artinya ke 26 mahasiswa tersebut mengalami peningkatan hasil belajar dari nilai pre test ke nilai post test, mean rank atau rata-rata peningkatan adalah sebesar 18,83, sedangkan rangking positif atau sum of ranks adalah 489,50 Berdasarkan output diatas "test Staistics" diatas diketahui symp. Sig (2-tailed) bernilai 0,004, karena nilai 0,004 lebih kecil dari < 0,005 maka dapat disimpulkan bahwa Hipotesis alternatif diterima artinya ada pengaruh penggunaan metode pembelajaran permainan bingo terhadap hasil belajar pada mahasiswa.

Disarankan sebaiknya untuk mengurangi kejenuhan mahasiswa dalam pembelajaran sebaiknya diselingi dengan metode permainan yang berkelompok. Bertujuan agar mahasiswa dapat bekerjaansama secara team, nantinya akan sangat berguna didunia kerja.

\section{DAFTAR PUSTAKA}

Nasution, Nur Baiti. 2017. Penerapan Pembelajaran Kooperatif Tipe Stad Dengan 
Permaian Bingo Untuk Meningkatkan Kemampuan Mahasiswa Dalam Mencari Turunan Dan Integral Fungsi. Delta : Jurnal Imiah Pendidikan Matematika

Mushfi, Muhammad. 2019. Bingo Game Method Upaya Meningkatkan Kemampuan Siswa Memecahkan Masalah Belajar Matematika. KEGURU: Jurnal Ilmu Pendidikan Dasar.

Oktaviani, Tian ., Endah Rita Sulistya Dewi, Kiswoyo. (2019). Penerapan Pembelajaran Aktif Dengan Metode Permainan Bingo Untuk Meningkatkan Hasil Belajar Matematika. Mimbar Ilmu. Universitas Pendidikan Ganesha.

Raharjo, Sahid. (2017). Contoh Kasus Uji Beda Mann Whitney menggunakan SPSS di https://www.spssindonesia.com/2017/04/uji-mann-whitney-spss.html?m=1 (dikases 20 April).

Sugiyono. (2019). Metode Penelitian Pendidikan. Bandung : Penerbit Alfabeta.

suktikno, Sobry . (2009). Belajar dan Pembelajaran, Bandung: Prospect. 